\title{
Students' ideas about technological systems interacting with human needs
}

\author{
Johan Lind ${ }^{1} \cdot$ Susanne Pelger $^{2} \cdot$ Anders Jakobsson $^{3}$
}

Accepted: 27 March 2018 / Published online: 30 March 2018

(C) The Author(s) 2018

\begin{abstract}
Technology is a compulsory subject at Swedish elementary schools and, according to the syllabus, helps students develop their ability to examine different technological solutions and reason how these solutions affect society, environment, and humans. An important challenge for educational research is to analyse and understand the consequences and impacts of technologies on students' learning, well-being, and participation in society. It is important to understand how technological systems work in order to orient oneself in modern society and to make well-informed decisions about what is good or bad use of technology. The purpose of this study is to further explore students' understanding of technological systems and their features through investigating the students' reasoning and collaboration in small-group interactions. We found a relatively large number of situations where students clearly demonstrate that they understand technological systems and the components and relationships among them. On the other hand, some situations indicate that students have difficulty explaining and understanding or realising concepts, theories, and relationships regarding technological systems. The findings need to be examined critically, although the students in this study were not used to this way of working with concepts or using images in their presentations. The study was conducted in the spring of 2016 at a compulsory school in the south of Sweden.
\end{abstract}

Keywords Technology $\cdot$ Technology education - Technological concepts · Technological systems $\cdot$ Components $\cdot$ Communication

Johan Lind

johan.lind@uvet.lu.se

1 Department of Educational Sciences, Lund University, Lund, Sweden

2 Faculty of Science, Lund University, Lund, Sweden

3 Faculty of Education and Society, Malmö University, Malmö, Sweden 


\section{Introduction}

In most Western countries, technology plays an increasingly important role as integrated parts of our way of living, thinking, and acting. For example, Säljö (2012) points to the development of hybrid minds, where humans' cognitive and communicative activities are increasingly dependent upon and intertwined with complex and powerful technological tools. In this way, technology may be described as human integrated systems that are connected to each other in web-like worlds, involved in society and in our lives to an extent that we risk taking them for granted. In this article, we argue that an important challenge for educational research is to analyse and understand the consequences and impacts of technologies on students' learning, well-being, and participation in society. However, an equally important and related issue is to explore how students understand this development of integrated technological systems and how it affects their lives. In this context, Klasander (2010) asserts that a high level of student awareness of technology and technological systems is crucial as we all are dependent on them, to some extent, and occasionally become parts of such systems. Further he argues, if students develop an understanding of the function of technological systems, this could, for example, facilitate a development of an ability to discuss and analyse issues about sustainable development and solve environmental problems in society. Klasander also notes that we need to understand how technological systems work in order to orient ourselves in a modern society and to make well-informed decisions about what is good or bad use of technology as committed citizens. Svensson (2011) argues that teaching about technology in context means focusing on technological systems as parts or components that are linked together to a meaningful wholeness. Furthermore, she asserts the significance of emphasising the involved artefacts in a systemic context and clarifying how the different parts interact in the system. In this way, technology education could contribute to support students' understanding of technology in its functional and human context without becoming reduced into separate or isolated artefacts. However, several researchers in the field (Hallström and Klasander 2017; Klasander 2010; Koski and de Vries 2013) have pointed out that the most common way of describing technological systems in education today is to use linear or hierarchical models in which the components are stacked without explaining how they are interrelated and work together.

During recent years, studies of students' understanding of technological systems have become an important aspect of technology education in Sweden and elsewhere. For example, Svensson (2011) found that students in compulsory school often have difficulty describing technological systems and the interaction between their components when the system is more or less hidden or invisible. Svensson et al. (2012) show that students seem to be able to describe specific artefacts correctly, but have difficulty putting them into a system context. The study also explored the students' experience and knowledge of how material, energy and information are transformed in technological systems. The results indicate that students tend to focus primarily on describing single components with little or no connection to the whole system and on describing systems only as an addition of components. Energy and information are seldom included. Koski and de Vries (2013) show that students describe machines as either consisting of different parts with various functions or as a number of activities to complete a process. Setting system boundaries turned out to be a demanding task for the students, as they needed knowledge about how the different parts in the system interact in order to achieve the desirable function. In Svensson's study (2011), the participating teachers also use images of technological systems in order to make components, functions 
and system boundaries explicit. Örtnäs (2007) also concludes that when students have the opportunity to use images or real artefacts as supporting and mediating tools, they become more able when it comes to describing the structure of the technological system.

In the present study, we explore how students aged 13-14 interact and collaborate in small-group discussions in order to understand and describe different technological systems and how they are constituted. The students' task was to independently choose an image on the Internet that they feel describes a technological system in a convincing manner, and together discuss how the system works. The purpose of this approach is to explore how students communicate their knowledge about technological concepts, components and systems, and how they work together in order to achieve a desirable function for humans; that is, to investigate how students understand the relationship between a technological system and its components. An underlying issue is to explore whether and, if so, how the students' descriptions are supported by the chosen images and whether these circumstances facilitate making the students' knowledge explicit.

\section{Theoretical background-technological systems}

The International Technology Education Association (ITEA 2000) defines a technological system as "a group of interrelated components designed to fulfil humans' needs and desires". Hughes (1993) uses a similar definition when describing a technological system as a system of complex, problem-solving components that solve problems or fulfil goals using available means. Further, Ingelstam (2012) and Bjurulf (2011) characterize technological systems as co-operating components and the relationship between them, in which the components together make new wholes and get new functions. Further they stress the human perspective even more through asserting that it is humans that create a technological system, that the system cannot make anything by itself, and that when it is used, humans become a part of it. In this latter view, a technological system is both a social and technological construction in which individuals are involved either as an independent component or as links between the components (Ingelstam 2012). However, when defining a technological system, we have to discern it from its environment, which means there must be a system boundary. One example of this is a washing machine, where the system boundary is the machine itself. However, the system interacts with its surroundings as inputs come from the environment, but inputs do not constitute the system as such. Furthermore, Ingelstam (2012) emphasizes that a large technological system is built out of several sub-systems, each of which could be divided into several sub-sub-systems, which creates a hierarchy of systems. In the above-mentioned example of the washing machine, the sub-system constitutes the electricity system in the machine where, in turn, the electrical circuit board becomes a sub-sub-system. Systems may also be sub-systems that include their own sub-systems. In other words, a component may also be defined as a system per se, with its underlying components. For example, the circuit board is a component in the washing machine, but could also be perceived as its own system with several components (such as transistors and capacitors). Therefore, in these contexts it is possible to extend the definition of a technological system by paying attention to the fact that, within the system, the sub-systems are linked together with internal inputs and outputs. 


\section{Technological systems as black boxes}

Today, it may be difficult to discover or explore many of the advanced technological systems because they do not provide the sufficient transparency. From an educational perspective, several researchers have emphasised (e.g. Koski and De Vries 2013; Svensson 2011) that if we want students to achieve knowledge about technological systems, this implies focusing on simplifying and making the systems explicit in technology education. However, this might be easier to express than to implement. Another way of describing these problems is to use Latour's (1999) black box metaphor by characterising modern technological systems as black-boxed (or a system as a black box). This expression may be used whenever a piece of machinery is too complex or hidden; then, a little box is drawn around this part, which implies that you do not need to know anything about what is inside the box except the input and output of the machinery to use it. Thus, without knowing the construction of the system and the characteristics of every component, you can still describe the system itself (Ingelstam 2012). Latour expresses this idea as follows:

[T] he way scientific and technical work is made invisible by its own success. When a machine runs efficiently, when a matter of fact is settled, one need focus only on its inputs and outputs and not on its internal complexity. Thus, paradoxically, the more science and technology succeed, the more opaque and obscure they become.

(Latour 1999, p. 304)

De Vries (2005) also illustrates a technological system by focusing on its input, process and output and describing the system's input and output by using matter, energy and information. Returning to the example of the washing machine, the input is electricity (energy), knowledge (information about how to handle the machine), washing powder (matter), clean water (matter) and laundry (matter), and its desired output is clean clothes (matter). The outputs that are not so desirable are wastewater, movement and heat. From this perspective, we can understand the washing process itself as black-boxed for us (de Vries 2005). The flow of information, matter, or energy and water in the system makes the function of the system possible. Thus, when describing the origin and goal of the flow, we need to define the system boundary towards its surroundings in order to make it possible to distinguish the system from the rest of the world (Svensson 2009). Svensson also points to that, from an educational perspective, it is important to follow the interaction between components in the system and the functions the components have in relation to the processes. This also includes the system's interaction with the surroundings and influences on nature, humans and other technological systems.

\section{System structures}

The structure of a technological system may be described in several different ways. For example, Klasander (2010) identifies four types of structures: linear models, circular orbit models, hierarchical and network models. According to the author, this division facilitates the discovery of the different character of the relationship between components in various technological systems. For example, when describing an electric circuit in a linear model, you put the components - battery, cord and bulb - in a row (from-to perspective) to achieve the desired description that becomes a circular orbit model when the circuit is closed. The 
network model focuses on how the components are connected; this is often described in a web-like mode (e.g. Hughes 1993). Several researchers (e.g. Ingelstam 2012; Trist and Murray 1993) have increasingly described technological systems as being sociotechnological systems (STS). This approach focuses on the interaction between humans and technology in workplaces from the perspective of complex organisational work design. The concept also refers to the interaction between society's complex infrastructures and human behaviour. In this sense, society itself, and most of its substructures, is comprised of complex sociotechnological systems.

\section{Components and artefacts}

According to Säljö (2005, 2012), we live in a world that could be described as one of artefacts that are created by humans for human purpose and action. Säljö also acknowledges that a characteristic of humans that separates us from other animals is that we create and use material artefacts, which become important parts of our social memories and thereby contribute to developing our individual skills and knowledge. In this way, experiences and inventions are preserved and integrated in the artefact and transmitted between generations (Gyberg and Hallström 2009). Jakobsson and Davidsson (2012) point to a similar process by asserting that an artefact and its user may be connected in a dialectic and reciprocal relationship where the artefact affects the user's thoughts and actions and the user can develop the artefact further by adding new inventions or applications. Moreover, de Vries (2005) argues that most new artefacts involve functional products of more than one part or component, which provide us with new conceptual systems. He also asserts that a new artefact may be understood as the outcome of an innovative, technological cognitive process in which existing components are put together in a new system. Furthermore, de Vries notes that artefacts enable us to perform an action that is necessary in order to get what we need or desire; for example, the washing machine provides us with clean clothes. However, technical artefacts can naturally have an endless number of other functions, such as transporting, transforming, creating and connecting (de Vries 2005). In this view, artefacts may also be considered as components and vice versa. This means that components are uniquely identifiable parts or subsystems that perform a function in a technological system; for example, a thermostat regulates the temperature of water in the washing machine. That is, a physical component and a well-defined functional part of a technological system. Svensson (2009) argues that students get a better understanding of human relation to technology if we use both artefacts (components) and systems when describing technology, thereby emphasising our own role in a technological system.

\section{Students' ideas on technological systems: previous research}

As mentioned, several studies (e.g. Svensson 2011; Koski and de Vries 2013) indicate that students often have difficulty describing technological inventions as an integrated overall system. Svensson (2011) stresses that technology education must support and scaffold students' awareness of systems and technology by uncovering functions and components that make the whole system explicit. In her study, the students' task was to describe technological systems by using everyday artefacts (a cellular phone, a bulb and a banana) and the related systems (cellular phone system, electricity system and banana transportation system). In the analysis of the answers, Svensson could discern three distinct dimensions in students' descriptions of technological systems, namely, resource, intention and structure. 
The most common way to describe the relation between a single artefact (component) and the system was to use a linear model, which implies that the students lined up the involved components to ensure that the necessary resources were delivered in a from-to perspective. For example, while the students displayed a satisfactory knowledge and understanding of cellular phone functions as such, they had difficulty describing the phone as an integrated part or component in a larger technological system. The students had problems relating the components to each other, describing the interaction between them, and describing the system as a whole. Further, Svensson (2011) concludes that students generally characterised technological systems by focusing on separable parts and nearly none of the students described them in terms of a web of interacting components.

In another study, Svensson et al. (2012) interviewed 15-year-old Swedish students about transport systems, energy systems and communication systems. In addition to these societal ways of handling material, issues about information were also included in the questions. To frame the interview situation, images and overall descriptions of the systems were included and the students were asked to visualise and communicate their ideas and understanding of the system. In the analysis, five different categories of understanding technological systems became clear: (1) using single components, (2) using the system output, (3) influencing the system, (4) interacting with the system, and (5) integrating the system. The authors also conclude that the most common way of looking at a technological system was to focus on single components without relating them to any system perspective, and to describe systems based only on the components included, excluding human and societal interaction with the system. Koski and de Vries (2012) explored primary students' understanding of different perspectives on technological systems. The researchers focused on whether the students could see a system as a structure of main- and subparts, whether they understood the input and output of a system, and whether they were able to put boundaries to a system. The general results indicate that the students showed a basic understanding of the fact that machines consist of parts with different functions and that several steps usually are required in order to complete a process in the system. Further, the students showed that the concept of input seemed to be more obvious than the output and that they understood output as what the systems produced in material terms. For most of the students, it was a challenging task to set system boundaries (see also Koski and de Vries 2013). Örtnäs (2007) also examined students' ideas of similar issues, but in the context of upper secondary students (age 14 and 17) and their perceptions of technological systems in their everyday lives. The researcher used semi-structured interviews and students were encouraged to draw pictures as a scaffolding tool during the interviews. Furthermore, the researcher initiated the conversation through using images of artefacts that were linked to the technological system in question. In the analysis, Örtnäs distinguished six different areas upon which students focused in their descriptions of technological systems: (1) the system's function, (2) the structure of the system, (3) the size of the system and the system's boundary to the surroundings, (4) the role of the human, (5) the connection in the system, and (6) the system's shape. The results also showed that the students were able, to a relatively large extent, to describe different systems in their everyday life, especially when they had access to images of the systems. The analysis also showed that the students were able to use the images to discover the structure of the system and the sub-systems, and to discuss the connection between humans and technology. However, with respect to this, the results highlighted significant differences between the age groups of students when it comes to describing integrated components and the use of technical words. The older students (17 years) had usually developed a more appropriate and subject-oriented language in technology than the younger ones (14 years). 
Another study (Hallström and Klasander 2017) investigated student teachers' conceptions of technological systems. The results of the study reveal that a relatively large number of student teachers also had difficulty describing and explaining different types of technological systems. This applies especially when it comes to explaining the invisible or abstract aspects of a system and describing the output and structure of technological systems. The authors conclude by asserting the need for student teachers and teachers in technology to develop an awareness in system thinking.

\section{The study and research questions}

The purpose of this study is to further explore students' (age 13-14) understanding of technological systems and their features through investigating the students' reasoning in smallgroup interactions. The students' task is to describe and explain an optional technological system by using an image that they had chosen from the Internet. The aim of this approach is to analyse how students communicate their knowledge about technological concepts, components and systems, and how this knowledge works together in order to achieve a desirable function for humans. An underlying issue is to explore whether and, if so, how the students' descriptions are supported by the images, and whether these circumstances make the students' knowledge explicit. The research questions in the study are as follows:

1. In what ways do students demonstrate their understanding of the concept of technological systems and the relationship between systems and components?

2. In what ways do digital images support students' communication when presenting in a group?

\section{Methodical considerations and analytic perspectives}

\section{Setting and participants}

The study was conducted in a municipal school in the south part of Sweden and followed the technology education in one class of 36 students over a 4-week period. When the students worked more practically or in small groups, the class was divided into two parts, with 18 students in each group. The data collection was performed in a year 8 class, in which the students are 13-14 years old and usually have minimal experience of technology education. The reason for exploring a relatively small group of students' ideas about technology is related to the research questions in this study. This implies that our interest is primarily focused on students' understanding of technological systems and the relation between systems, components and humans when they work independently in small groups. Our starting point is that the students' understanding of the concepts may become obvious and explicit when they collaborate on these issues. In these situations, the students were expected to discuss and reason on the basis of the images they chose to represent technological systems. That implies that we, as researchers, view the individual participants as contributing to existing and operating discourses that become observable in action when reasoning about technology (Wertsch 1998; Jakobsson et al. 2009). The original images, which were chosen by the students, are here replaced with sketches for copyright reasons. You will find links to the original images under references. 
During the 4-week school project, technological systems and humans' relationships with technology were important elements and objectives. The students were asked if they would like to participate in the study and, if so, received an information letter for them and their parents to sign. All of the students and their parents chose to give their consent to participate in the study. This has been very important in terms of gathering reliable data, as the students were expected to share their thoughts, ideas and knowledge about the education and the content. The school performs relatively highly, in the sense that most students obtain high results on national tests (Skolverket (Swedish National Agency for Education) 2016a, b). In Sweden, technology is an independent subject in compulsory school with its own syllabus, which includes aims, core content, knowledge requirements and support material. One aim in the curriculum (Skolverket (Swedish National Agency for Education) 2011) is to give students opportunities to develop their ability to identify problems and needs that can be solved by means of technology and to identify and analyse technological solutions based on their function. There is also a focus on students' learning of how components and subsystems work together in larger technological systems. Further, students should increase their understanding of technological solutions in the society and develop knowledge about how the interaction between artefacts, components and systems create desirable functions for humans.

\section{Collecting data}

An important aim of this study has been to come close to students' thoughts and ideas about technological systems and their understanding of the relationship between components, systems and humans. As mentioned, we were also interested in collecting data about the students' choice of representations of technological systems in the form of images from the Internet, which may facilitate our interpretation and understanding of the students' ideas. In order to collect classroom data, which may create opportunities to answer our research questions, we have mainly used video recording of student conversations in small groups (three or four students) and focused on their activities during full-class teaching situations. All of the students' images from the Internet have also been collected. According to Goldman et al. (2014), video recording in the learning sciences facilitates and clarifies the analysis of the collected data because gestures and body language are important, together with identification of the students. The video data has been of particular importance as the conversations between the students often focused on the chosen images and the details therein. Thus, this type of data constitutes a dominant part of the total amount of data in the study and we have, with help of the recordings, managed to identify all images of the technological systems that the students discuss. A possible hypothesis is that the images constitute an important cognitive tool that can support students' reasoning, help make their thinking about complex technological systems explicit, and help them to put words to their thoughts. Cohen et al. (2013) assert that the use of visual data and images may expand the linguistic repertoire of the informants and enable them to formulate non-pronounced thoughts. Further, according to the Swedish National Agency for Education (Skolverket (Swedish National Agency for Education) 2011) the specific subject language (Hajer and Meestringa 2014) is a key to developing and displaying knowledge in all subjects. The subject language in technology involves being able to express, interpret and use concepts, facts and key ideas in speech and in writing, but also the feelings and opinions that the subject arouses (Skolverket (Swedish National Agency for Education) 2016b). Consequently, we have also placed particular focus on the students' use of words and expressions when discussing technological systems (e.g. Serder and Jakobsson 2016). 


\section{The analytic process}

The analytic procedure in the present study consists of three separable but interrelated phases. In the first phase of the analysis, all of the collected data were carefully reviewed, and contentrelated situations during students' discussions about technological systems and the selected images were selected for further analysis (approximately $31.5 \mathrm{~h}$ ). During this phase, we also searched for the students' images on the Internet by using Google's image search and successfully found the source of all images. This procedure implied that we could relate the students' individual statements to specific images and thus improve our understanding of their utterances further on (Goldman et al. 2014). In the second phase, we focused specifically on situations in which the students more explicitly explained or defined concepts such as technological systems, components and artefacts. This includes situations where the students talked about human interactions with technological systems and technological innovations. All of these situations were carefully transcribed and constitute the main material for the in-depth analysis of the students' statements and reasoning (approximately $3.5 \mathrm{~h}$ ). The analysis in this phase also implies that we could focus on our research question in more detail. However, we interpreted all transcriptions as adaptations of digital recordings, which in this respect is the primary material (Burges 2010). The transcripts were initially made in the form of rough transcriptions, which have since evolved gradually during the analysis. They have been designed with the aim of focusing on what students are talking about and how they express themselves in relation to the content. Our analyses assume a sociocultural theory, which implies that students' through technology education are socialised into scientific ways of reasoning and acting (Vygotsky 1986; Säljö 2012). By encountering the specific distinctions and practices in technology, students are guided into recognising and using particular discursive patterns, which often differ from other discourses in society. In line with this, we used Lemke's (1990) thematic patterns as an analytic tool in the third phase. Thematic patterns draw on specific semantic relations, which are observable as rhetorical structures, figures of speech, and other forms of accountable talk and action played out in classroom activities. In this view, the process of studying students' knowledge and understanding in technology becomes a process of studying students' ability to use language in relevant ways while engaged in a school activity; that is, to analyse how students are able to formulate themselves when reasoning, arguing and learning in situated activities (Jakobsson et al. 2009). By studying how students "talk technology" while engaged in project work, it is also possible to find and describe instances of language use that seem particularly easy or difficult to appropriate. In the "Results" section, we aim to describe examples from these situations, thereby clarifying what concepts the students perceive as complex and difficult to comprehend and which ones they find it easier to understand. Our aim is also to summarise the students' difficulties and opportunities when it comes to understanding technological systems in an overall model at the end of the "Results" section.

\section{Results}

In total, 63 group discussions were video-taped and analysed. In the following, the students' ways of reasoning about technological systems will be illustrated with excerpts from three of the groups. These excerpts were selected because they are representative of the entire material and help us to answer our research questions.

In the first example (excerpt 1a), Billie, Nina and Robyn discuss different technological systems, the ingoing components and the relationship between them based on the images 
they have chosen as support for their presentation. The conversation starts when Billie (107) shows a picture of the heating systems and heat transport in a house.

\section{Excerpt 1a}

Example of group discussion

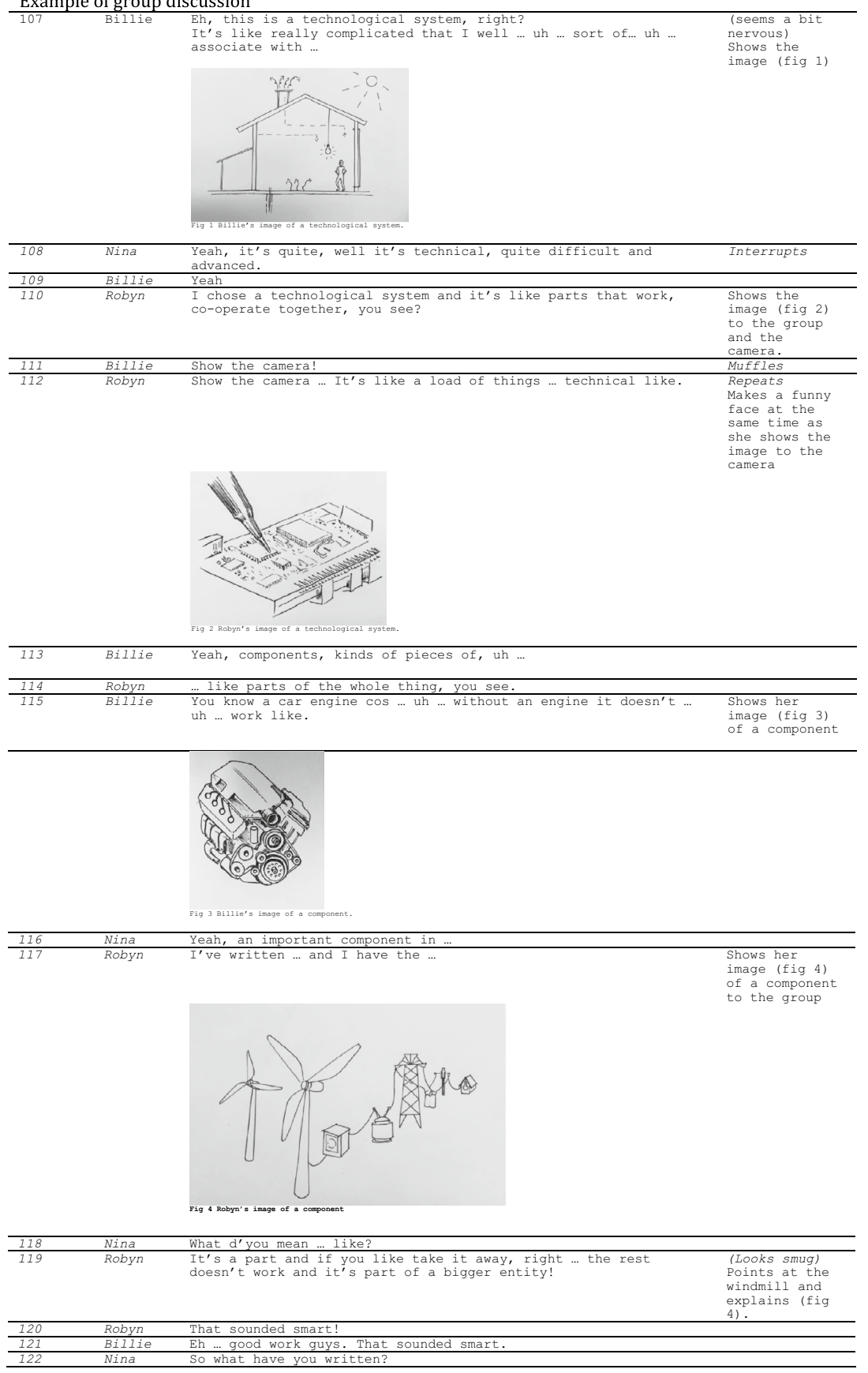


The conversation starts when Billie asserts that the image she has chosen is really complicated (107), but is interrupted by Nina when she intends to explain further on. Nina supports the idea that Billie's technological system is sophisticated by saying, well it' $\mathrm{S}$ technical, quite difficult and advanced(108), which indicates that students are not used to interpreting images of advanced technological systems. However, Robyn continues the discussion, trying to formulate a definition of a technological system by asserting, I chose a technological system and it's like parts that work, co-operate together you see? (110). She continues her reasoning by arguing ... like a load of things ... technical like(112). Billie completes and extends the definition by claiming that it is also... components, kinds of pieces of eh ... (113). With this statement, she introduces the concept of components and later gives an example by emphasising that ... a car engine cos ... uh ... without an engine it doesn't ... uh ... work like (115). Even Robyn seems to be on this thought when she says that a component is ... like parts of the whole thing ... (114). The conversation then continues when Robyn displays her image and argues that a component It's a part and if you like take it away ... the rest doesn't work and it's part of a bigger entity! (119).

A possible interpretation so far is that Billie and Robyn seem to have reached a joint agreement on that a technological system consists of cooperating components, which constitutes a whole, and that if a component is missing, it implies that the system will not work. Robyn's statement (119) reinforces this conclusion further on as she emphasises that the functioning of the system depends on its constituent parts. Moreover, the example of the car engine may indicate a possible understanding of the system boundaries of a technological system. However, such a conclusion cannot be drawn with certainty from this example. When it comes to the students' use and support of the images, it is obvious that, for example, Billie uses the image as a backing of the argumentation about the components (car engine). The same applies to Robyn when she clarifies the dependency of the entire system (the energy supply system) on individual components (the windmill). In addition, it is reasonable to assume that the chosen image may give a clue about how the students understand and perceive technological systems and components, at least when relating their images to their statements. For example, Robyn points to the windmill as a part of the energy system when the group discuss components, which implies that she is aware of what constitutes a component in a technological system. However, some features of technological systems and components never really come up in the negotiation in the group; for example, if the students understand the components in their systems as a row with a from-to perspective, or if they would describe them in more web-like terms. Likewise, they never clarify that a single component itself can constitute a technological system in terms of subsystems, nor do they mention the input and output of the system.

The second example clarifies the previous situation when the teacher in a full-class discussion asks Robyn what she has noted about technological systems. The excerpt begins when Robyn starts to read from her notes. 


\section{Excerpt 1b}

\begin{tabular}{llll} 
Example of whole-class discussion \\
\hline 128 & Robyn & um ... d'you want me to read what I've written, like? & Unsure \\
\hline 129 & Teacher & That'll be fine. Go ahead. & \\
\hline 130 & Robyn & $\begin{array}{l}\text { Like, well, technological systems, like in our ipads, are small } \\
\text { systems that work well as a large technological system ... }\end{array}$ \\
\hline 131 & Jonathan & $\begin{array}{l}\ldots \text { electrical circuits; for example, where you put a micro-chip } \\
\text { in a computer ... [pauses] it creates an electrical system and } \\
\text { then the computer can be part of a technological system }\end{array}$ & $\begin{array}{l}\text { Breaks in when } \\
\text { Robyn pauses }\end{array}$ \\
\hline 132 & Teacher & A technological system & Clarifies \\
\hline 133 & Jonathan & Yeah, right ... a technological system & \\
\hline
\end{tabular}

When Robyn is due to explain the concept technological system in the whole-class context, she chooses to express her ideas in a different way than in the earlier group discussion. This indicates uncertainty about whether the group's mutual definition was correct or not and she chooses to read her written explanation. In this situation, she does not involve the word "component" or the chosen image to support her presentation. Instead, she asserts that... technological systems, like in our iPads, are small systems that work well as a large technological system ... (130). In this utterance, she describes the system as large and small, which was never mentioned during the group discussion. However, it is possible to interpret the statement, as she is aware that an iPad is a technological system consisting of other underlying systems and that they are connected to one another. However, it is difficult to determine whether she also refers to the fact that the iPad is part of a larger technological system (such as the Internet), as well as the sub-systems in the iPad. When Robyn makes a short pause, Jonathan breaks in without the teacher's request and continues Robyn's utterance. He seems to focus on both possibilities by expressing ... electrical circuits; for example, where you put in a micro-chip in a computer ... it creates an electrical system and then the computer can be part of a technological system (131). Thus, Jonathan builds on Robyn's utterance and emphasises that one of the small (130) systems that Robyn talked about consists of electrical circuits (131), which together with a micro-chip ... creates an electrical system (131). However, it is somewhat unclear what he is referring to when he then claims ... the computer can be part of a technological system(131). One potential meaning could be that he is referring to the fact that the electrical systems in the computer contribute to it being complete and functioning and that it can be used as a technological system. A more likely interpretation is that he actually wants to emphasise that the computer itself consists of several technological systems (electrical systems, for example), constitutes a technological system itself (iPads and computers) and that it can also be part of a larger technological system (connected to networks). In that case, it is possible to claim that Jonathan is aware that a component in a larger system actually may constitute a technological system itself. In any case, he may have developed some ability to express the fact that technological systems are interrelated and that they interact with each other.

In the next example, Magnus, Chris and Alfons discuss technological systems based on their self-chosen images (excerpt 2). The situation starts when Magnus displays his image of a bike. 


\section{Excerpt 2}

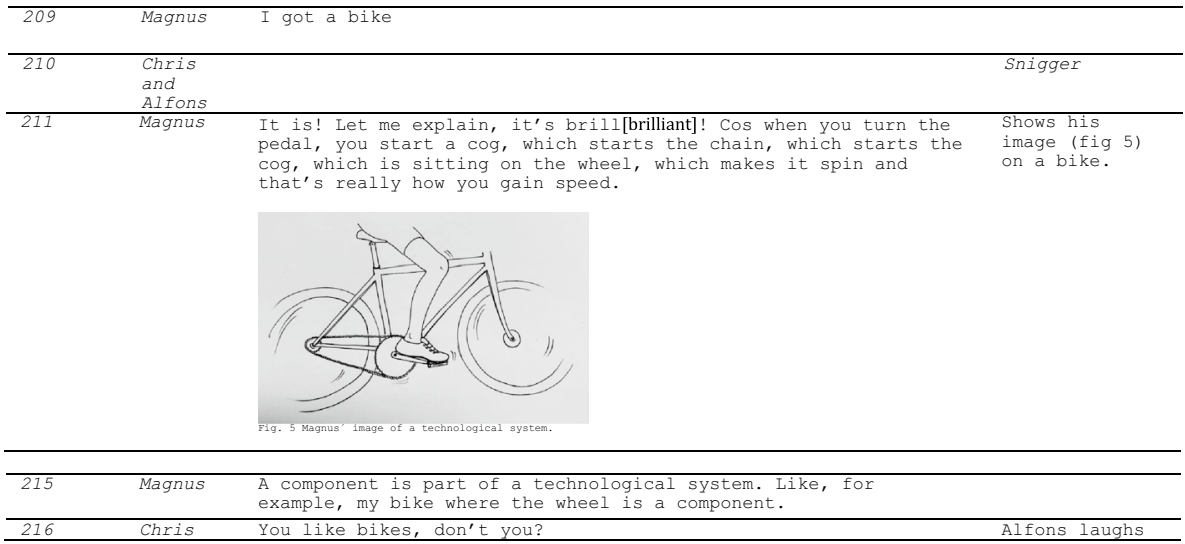

Magnus initiates the discussion by saying I got a bike (209) and thereby indicates that he has chosen an open technological system where most of the components are visible and possible to identify. This means that the bike as a system is mainly not black-boxed (Latour 1999). However, we cannot say from the excerpt that this is a conscious choice on Magnus's part. On the other hand, we can assert that the choice of a bike to represent a technological system makes it easier for him to display how the various components interact. This indicates that he has processed the concept of component enough to understand the meaning and then selected the image of a bike as it fitted his purpose. Nevertheless, he then starts to explain and clarify the relationship between the pedal-chain wheel-chainpinion-rear wheels by expressing... when you turn the pedal, you start a cog that starts the chain, which starts the cog, which is sitting on the wheel, which makes it spin and that's really how you gain speed (211). In this statement, it becomes obvious that he not always uses the correct terms, while his reasoning clearly indicates that he expresses an understanding on the relationship and interaction between the components in a system. This conclusion is further reinforced when he also expresses that $A$ component is part of a technological system. Like, for example, my bike where the wheel is a component (215). Moreover, Magnus's statements show that he is aware of how the constituent components co-operate to achieve a specific function in order to create a desirable technological system. However, it is not obvious that he knows that a technological system consists of subsystems, which is one of Klasander's (2010) criteria when describing technological systems. In Magnus's utterance, the components are lined up in a from-to perspective, which is probably the most suitable in this case. One could interpret the end of the first statement-that's really how you gain speed (211) — as him referring to the input and output of the system without mentioning the concepts themselves. By using the word you (211), Magnus emphasises that the system needs energy from the surroundings to work, in this case energy from a human. The students in Svensson's (2011) study considered resources, intentions and structures as characteristics that describe technological systems. In the present study, Magnus's use of the word 'you' could refer to the resources that humans bring to the system to obtain a desirable function. 
When it comes to the image, it is likely that the image of the bike supports and reinforce Magnus's reasoning of what constitutes a component and a technological system. This means, for example, that the image helps him to remember the order of the components, which facilitates his argumentation. In these contexts, Säljö (2005) asserts that images may work as artefacts that support our memory, make our thinking explicit and helping to mediate thoughts that we have never thought before. One might argue that the images of the technological systems in this study become external memory systems and mediational means for the students.

In our last example (excerpt 3), Henry, Jonas, Freddy and Elmore also discuss their images of technological systems and components.

\section{Excerpt 3}

\begin{tabular}{|c|c|c|c|}
\hline 303 & Henry & Technological systems first. & \\
\hline 304 & Jonas & Tell us about it then. & \\
\hline 305 & Henry & When components work together ... & \\
\hline 306 & Freddy & Yeah, what is a component, tell us what it is? & Impatient \\
\hline 307 & Henry & Like a battery, like. & See fig 6 \\
\hline 308 & Jonas & I've actually got a good one there. & \\
\hline 309 & Freddy & Ah. & $\begin{array}{l}\text { Nods in } \\
\text { recognition }\end{array}$ \\
\hline 310 & Jonas & A computer is a rather good example of a technological system. & $\begin{array}{l}\text { Shows an image } \\
\text { of his father's } \\
\text { computer (not } \\
\text { visible on the } \\
\text { video } \\
\text { recording) }\end{array}$ \\
\hline 311 & Elmore & No it's not. & \\
\hline 312 & Freddy & In a computer there are many components. & \\
\hline \multirow[t]{2}{*}{334} & Henry & A battery's got to be a component. & \multirow[t]{2}{*}{$\begin{array}{l}\text { Shows an image } \\
\text { of a battery } \\
\text { (fig 6) }\end{array}$} \\
\hline & & Fig 6 Henry's image of a component & \\
\hline 335 & Freddy & Yeah, it is. & \\
\hline 336 & Elmore & Nah. & Shakes his head \\
\hline 337 & Jonas & But I don't play. & \\
\hline 338 & Freddy & Course it is. & \\
\hline 339 & Elmore & I think it is a technological system ... a battery. & \\
\hline 340 & Freddy & Quite really I have no idea. & \\
\hline 344 & Freddy & I don't get what a component is. & \\
\hline 345 & Henry & $\begin{array}{l}\text { It's something that makes ... I don't know ... something else work in a } \\
\text { technological system. }\end{array}$ & \\
\hline 346 & Freddy & It's something that you use in a technological system. & \\
\hline 347 & Jonas & It's a part you put together in a technological system. & \\
\hline 348 & Elmore & $\begin{array}{l}\text { Components are different kinds of parts in electrical devices that } \\
\text { make other devices work. }\end{array}$ & \\
\hline 349 & Freddy & Yeah, but it still doesn't say what it is, right? & \\
\hline
\end{tabular}

At the beginning of this excerpt, Henry makes it clear that a technological system can be described as When components work together .... (305). However, Freddy does not appear to be satisfied with this answer and urges Henry to develop it further and explain what a component actually is. Henry responds with an example of a battery (307). He does not further develop this reasoning because Jonas simultaneously emphasises that A computer is a rather good example of a technological system (310). Jonas continues his reasoning about computers and claims that In a computer there are many components (312). Through this statement, he expresses some knowledge of what a component may be. However, Elmore does not take this thread on computers but turns to Henry and says No it's not (311); in other words, he questions Henry's claim that a battery is a component. Henry does not immediately respond to this 
but, after a short moment of silence, he picks up his image of a battery and some more hesitant claims that A battery's got to be a component (334). This time, Jonas actively supports him (335), while Elmore still questions his claim (336). Henry finally formulates his rebuttal and says: I think it is a technological system ... a battery (339). This counter-argument appears to create some uncertainty among the others, which leads Freddy to say, ... I have no idea (340) and later I don't get what a component is (344). On the other hand, Elmore's argument also provides an in-depth discussion of what a component really is and how to define it. Henry starts the discussion by expressing that a component is ... something that makes ... [it] ... work in a technological system (345). Freddy and Jonas further complete the statement by adding, It's something that you use in a technological system(346) and ... a part you put together in a technological system (347). Elmore focuses on the electrical parts when he asserts that Components are different kinds of parts in electrical devices that make other devices work(348). All of these statements actually constitute various attempts to define the concept of component, but may also be seen as a willingness to create a joint definition of the concept in collaboration. Freddy concludes this short discussion by saying: ... but it still doesn't say what it is ... (349). Through this statement he probably wants to emphasise that they still not have a uniform and unambiguous definition of the concept of component.

We argue that this excerpt constitutes an example of students demonstrating a relatively developed knowledge of components and technological systems simultaneously as they express some shortcomings or misunderstandings about the concepts. For example, at the start of the excerpt Henry defines a technological system as a system in which components work together (305) and most of the students are able to provide examples of systems and their components (computers and batteries). However, different views arise regarding whether batteries can be counted as components or as complete technological systems. Henry argues that a battery is a component (307) and Elmore that it is a technological system (339). The example of the battery is complicated as the system is black-boxed for the viewer (Latour 1999). The different ideas divide the group but also lead to a productive conversation about the issue. The conclusion that something can be both a component in a system and a system in itself never appears in the discussion. Moreover, this particular and double relationship between components and systems constitutes relatively abstract knowledge, while also providing an essential prerequisite for developing a deeper understanding of technological systems. We would also like to highlight the final discussion in the excerpt as an example of a process of common definition of the concept. All of the students individually provide a correct contribution to such definition simultaneously, as the individual contribution is not enough to formulate the definition alone. However, the group never reach an unambiguous and commonly agreed definition, which Freddy also points out at the end (349). A possible alignment to enhance the conversation could be to ask the students what kind of input and output the battery has or to explore it from the inside.

\section{Summary of the results}

In our analysis of the excerpts and in the overall data material we have found examples of situations in which concepts, theories and relationships regarding technological systems cause obvious problems among the students. This means situations in which most of the students clearly indicate that they do not understand a concept or realise its meaning. 
On the other hand, we also have a relatively large number of situations in which students clearly demonstrate that the concepts and relationships between them do not cause such problems. Our examples of excerpts display both types of situation. Our intention is now to try to summarise the knowledge area of technological systems from the perspective of how students in this study perceive and understand it. We also intend to suggest an overall model (Tables 1,2,3) that describes the opportunities and problems that may arise when students try to make sense of technological systems. Where possible and appropriate, we intend to compare our analysis with the results of other studies to create as reliable a model as possible. We do not claim that our model is complete or that it covers all the issues and opportunities that the area encompasses. Nor should our suggestions be interpreted as a claim that knowledge about technological systems is linear or that learning in this area is built on hierarchical principles. Based on the results of this study, it is not possible to express valid statements about this.

Thus, the analysis of the excerpts resulted in three main categories describing how students use the concepts related to technological systems and components and how these may be interconnected. The main categories, together with the underlying sub-categories, are an attempt to structure the subject content that the students talked about during the discussions. For example, the students used different conceptual systems when describing technological systems, which are displayed as sub-categories in Table 1. This means that technological systems can be open or closed, that the systems scale and complexity are continuous from the simple to the advanced, and that a technological system could be a component in another technological system.

Most of the students in the study had no problem describing a technological system as consisting of different parts (components) and that these parts work together to create a desirable function. For example, Magnus (excerpt 2) described the wheel on a bike as a component in a technological system, and Jonas (excerpt 3) put the components together in a computer to explain a technological system. In this context, Bjurulf (2011) stresses that technology education should not only include specific components and artefacts without relating them to the broader context in which they fulfil desirable functions. In the third excerpt, the students' contrasting explanations on a battery became explicit when Henry understood the battery as a component and Elmore described it as a technological system. However, none of the students expressed that the battery could

Table 1 Overall categories describing how students use the concept of technological systems and components

\begin{tabular}{ll}
\hline Main category & Sub categories \\
\hline $\begin{array}{l}\text { A. Technological systems consisting } \\
\text { of components }\end{array}$ & $\begin{array}{l}\text { Open systems and closed systems (black-boxed) } \\
\text { The systems scale and complexity (from simple to more advanced) } \\
\text { Technological systems as components in other technological } \\
\text { systems }\end{array}$ \\
B. Components as part of a whole & $\begin{array}{l}\text { Components working together to achieve a desirable function } \\
\text { Missing component changing the system or its function }\end{array}$ \\
& $\begin{array}{l}\text { Components as technological systems } \\
\text { Components lined in a row; a 'to-from' perspective } \\
\text { C. Structure of technological systems } \\
\end{array}$ \\
& $\begin{array}{l}\text { Input and output of the system } \\
\text { Components structured in a web; a web-like perspective } \\
\text { Sub-systems and hierarchies }\end{array}$ \\
\hline
\end{tabular}


Table 2 Categories describing students' use of technological terms without mentioning the subject-specific terms
Main category

D. System control, feedback, flow and information

E. System boundary and system surroundings

F. Socio-technological perspectives

be either, depending on the context. We argue that it is central and important to express the principle that a technological system can be a component of another technological system. This would imply an understanding of the relation of components and systems and the idea that new inventions in technology often put smaller parts or systems together to achieve a new technological system that solves a formulated problem.

Further, some of the students tended to view components as a part of the whole without mentioning that the parts' functions interact with each other to create a working whole. For example, Robyn described components in a circuit board as parts of the whole thing or as parts of a bigger entity (excerpt 1a). However, she mentioned that if you take one part away, it will influence the rest of the system. These results are in line with Svensson's (2009) study. When it comes to describing the structure of technological systems, Magnus (excerpt 2) used a schematic image of a bike to explain how the different components interact to make the wheel spin. In this description, he also included human interaction as a prerequisite for the system to function. It may also be noted that, when choosing an image, he chose an open system that makes the components visible and easier to describe. Svensson (2011) found that a large proportion of students show that they have difficulty connecting the different components to each other and explaining how they work together. Similar difficulties were also found in this study. However, in excerpt 3 Elmore stressed that components are different parts in electrical devices that make other devices work when he argued that a battery is a technological system. This way of arguing could indicate that Elmore understood systems in a more web-like perspective, although more examples are needed in order to say this with certainty.

It is rarely possible to describe technological systems based on theoretical terms, such as, system boundary and socio-technological perspectives. However, there are situations when students used the content of the concept without mentioning the term itself. We have summarised this type of underlying concepts in Table 2.

The concepts in Table 2 describe technological systems in a more advanced and abstract perspective and, above all, aim to put the systems in a broader context. As mentioned, the students did not actively use these terms, but occasionally discussed similar content. For example, the students in excerpt 3 vigorously discuss whether a battery may be considered as a technological system or a component without reaching a joint solution. However, to understand that a battery can be understood simultaneously as a technological system and as a component in another system can help students to understand the principles of

Table 3 Categories describing possible areas of expanding the group discussions
Main category

G. Co-operation in larger systems

H. Global technological systems; e.g. the Internet

I. Areas of use (possibilities and risks) 
a systems boundaries, surroundings and flow. In other words, it can help them understand that technological systems and components, as concepts, can be regarded as relative concepts where the environment and human interactions with the systems need to be described in order to decide what is what (Svensson 2011). We also argue that the concepts in Table 2 are important in technology education because their explicit use helps students to put words on crucial principals about technological systems. The table also provides examples of concepts that students in this study perceived as relatively abstract and complicated, thus offering a tool for teachers in technology who want to expand their students' understanding.

Finally, there are content-related principles of technological systems that none of the students mentioned or related to at any time during the discussions (see Table 3). Students in our study seemed to need support and input from teachers, or other learning tools, such as study material. The main categories in Table 3 could be seen as areas of possibility to expand the teaching further. Together, Tables 1, 2 and 3 form our proposal for a model that forms a teaching strategy on technological systems.

\section{Final discussion and implications}

The main purpose of this study has been to explore how students understand technological systems and the relationship between different systems and their components. It has become clear in our analyses that there are underlying concepts and principles of technological systems that have different levels of difficulty and complexity for students in compulsory school (aged 13-14). Using a summary of these analyses and results from other studies, we have concluded that students' perceptions and knowledge about technological systems seem to be divided into three levels of difficulty, which we have compiled in three tables. The first level (Table 1) consists of concepts and principles that a relatively large number of students actively use and seem to comprehend when discussing these issues. However, it is important to emphasise that this does not apply to all students and that certain principles and concepts on this level are experienced as more difficult than others. This applies, for example, to the principle that a technological system could be a component in another technological system or to view systems in a web-like perspective. Nevertheless, Table 1 aims to describe the concepts and principles of a technological system that most of the students in our study perceived as concrete and relatively easy to understand. The main categories of Table 1 are that technological systems consist of components, that a component is a part of a whole, and the structures of the technological systems. These results are mainly in line with the conclusions in other studies (e.g. Svensson et al. 2012). The other two levels consist of concepts and principles that are perceived to be considerably more abstract and difficult for the students to encompass (see Tables 2, 3). The middle level (Table 2) consists of concepts and principles that students discussed only implicitly, and the highest level (Table 3) comprises concepts and principles that none of the students mentioned at any time during the study (Table 3). For example, none of the students mentioned or related to the terms 'system boundaries' or 'system flow' at any time during the discussions.

An important implication is that the concepts and principles in Tables 2 and 3 need explicit attention in technology teaching in compulsory school. By giving students the opportunity to learn to use the correct terms, they will acquire a technical language that facilitates their understanding. We argue that the ability to put more precise terms on the 
thoughts and ideas the students express may be defined as a kind of knowledge development in this context. Another important conclusion is that the students' joint discussions have been of crucial value for their knowledge development and their ability to express themselves about technological systems. One example of this is the discussion in excerpt 3 , where the students express different hypotheses about whether a battery may be considered as a component or a technological system. However, the group does not really solve the problem, but it does create an explicit need to define the different things. The discussions also clarified different perspectives from the members of the group and could contribute to developing students' awareness of critical perspectives on important society decisions in the future, effects of technological solutions in society and daily life choices. A conscious teaching strategy could actively support the development of this awareness. First, it implied that the students received examples of different types of technological systems from the relatively simple to considerably complex. Second, the individual presentations of the chosen image forced reflection and argumentation about how the chosen system could be defined as a technological system. Third, the choice of an image meant that the students' thoughts and ideas about technological systems and components became explicit. As part of such a strategy, we suggest letting students choose images as a representation of a technological system. This way, teachers could gain insights into students' prior knowledge and possible misconceptions. In addition, the process of explaining, comparing and justifying their choice of images could help advance students' understanding of technology.

Acknowledgements This work was financially supported by the research school "Communicate Science in School" (CSiS) and the Swedish Research Council (Dnr 2013-6848).

Open Access This article is distributed under the terms of the Creative Commons Attribution 4.0 International License (http://creativecommons.org/licenses/by/4.0/), which permits unrestricted use, distribution, and reproduction in any medium, provided you give appropriate credit to the original author(s) and the source, provide a link to the Creative Commons license, and indicate if changes were made.

\section{References}

Bjurulf, V. (2011). Teknikdidaktik—Vad, hur och varför? [Technology didactics—What, how and why?]. Riga: Norstedts.

Burges, R. G. (Ed.). (2010). The research process in educational settings: Ten case studies (Vol. 168). London/New York: Routledge.

Cohen, L., Manion, L., \& Morrison, K. (2013). Research methods in education. New York, NY: Routledge.

De Vries, J. M. (2005). Teaching about technology—An introduction to the philosophy of technology for non-philosophers. Dordrecht: Science and Technology Education Library, Springer.

Goldman, R., Pea, R., Barron, B., \& Derry, S. J. (Eds.). (2014). Video research in the learning sciences. New York, NY: Routledge.

Gyberg, P., \& Hallström, J. (2009). Världens gång-teknikens utveckling [The world's movement-The development of technology]. Lund: Studentlitteratur.

Hajer, M., \& Meestringa, T. (2014). Språkinriktad undervisning. En handbok [Language-oriented teaching. $A$ handbook]. Stockholm: Hallgren and Fallgren.

Hallström, J., \& Klasander, C. (2017). Visible parts, invisible whole: Swedish technology student teachers' conceptions about technological systems. International Journal of Technology and Design Education, 27(3), 387-405. https://doi.org/10.1007/s10798-016-9356-1.

Hughes, T. P. (1993). The evolution of large technological systems. In W. E. Bijker, T. Hughes, \& T. Pinch (Eds.), The social construction of technological systems. New directions in the sociology and history of technology (pp. 51-82). London: The MIT Press. 
Ingelstam, L. (2012). System-Att tänka över samhälle och teknik [System-Thinking of society and technology]. Eskilstuna: Energimyndigheten.

International Technology Education Association. (2000). Standards for technological literacy: Content for study of technology, 3rd edn. Reston, US: International Technology Education Association. https:// www.iteea.org/File.aspx?id=67767\&v=b26b7852. Accessed November 3, 2017.

Jakobsson, A., \& Davidsson, E. (2012). Using sociocultural frameworks to understand the significance of interactions at science and technology centers and museums. In E. Davidsson \& A. Jakobsson (Eds.), Understanding interactions at science Centers and Museums. Rotterdam, NY: Sense Publisher.

Jakobsson, A., Mäkitalo, Å., \& Säljö, R. (2009). Conceptions of knowledge in research on students' understanding of the greenhouse effect: Methodological positions and their consequences for representations of knowing. Science Education, 93(6), 978-995.

Klasander, C. (2010). Talet om tekniska system-förväntningar, traditioner och skolverkligheter [The talk of technical systems-Expectations, traditions and school realities]. Norrköping: FontD Linköpings Universitet. http://www.diva-portal.org/smash/get/diva2:395176/FULLTEXT01.pdf. Accessed July 18, 2017.

Koski, M-I., \& de Vries, M. (2012). Primary pupils' thoughts about systems. An exploratory study. Science education and communication (SEC). Technical University of Delft. http://www.ep.liu.se/ecp/073/030/ ecp12073030.pdf. Accessed November 3, 2017.

Koski, M.-I., \& de Vries, M. (2013). An exploratory study on how primary pupils approach systems. International Journal of Technology and Design Education, 23(4), 835-848.

Latour, B. (1999). Pandora's hope: essays on the reality of science studies. Cambridge, MA: Harvard University Press.

Lemke, J. (1990). Talking science. Language, learning, and values. Norwood, NY: Ablex.

Örtnäs, A. (2007). Elevers vardagsuppfattningar om tekniska system [Pupils' everyday conceptions of technical systems]. Linköping: Linköpings Universitet. http://liu.diva-portal.org/smash/get/diva2:23542/ FULLTEXT01.pdf. Accessed November 3, 2017.

Säljö, R. (2005). Lärande och kulturella redskap. Om lärandeprocesser och det kollektiva minnet [Learning and cultural tools. About learning processes and collective memory]. Falun: Norstedts Akademiska Förlag.

Säljö, R. (2012). Literacy, digital literacy and epistemic practices: The co-evolution of hybrid minds and external memory systems. Nordic Journal of Digital Literacy, 7(1), 5-19.

Serder, M., \& Jakobsson, A. (2016). Language games: The meaning potentials of scientific literacy surveys. Science Education, 100(2), 321-343.

Skolverket (Swedish National Agency for Education). (2011). Läroplan för grundskolan, förskoleklassen och fritidshemmet 2011 [Curriculum for the compulsoryschool, preschoolclass and the recreationcentre, 2011]. https://www.skolverket.se/laroplaner-amnen-och-kurser/grundskoleutbildning/grundskola/ laroplan. Accessed November 1, 2017.

Skolverket (Swedish National Agency for Education). (2016a). SiRiS—kvalitet och resultat i skolan [SiRiSquality and results in school]. http://siris.skolverket.se/. Accessed November 2, 2017.

Skolverket (Swedish National Agency for Education). (2016b). Språkutvecklande arbetssätt [Language development approach]. https://www.skolverket.se/. Accessed November 3, 2017.

Svensson, M. (2009). Från föremål till system: Mot en undervisningsstrategi i grundskolan [From artefact to system: Towards a strategy for education in primary school]. In A. Ingerman, K. Wagner, \& A.-S. Axelsson (Eds.), På spaning efter teknisk bildning [On the look for technical literacy] (pp. 207-221). Stockholm: Liber.

Svensson, M. (2011). Att urskilja tekniska system — didaktiska dimensioner i grundskolan [To discern technical systems—didactic dimensions in primary school]. DIVA: Linköpings Universitet. https://www. diva-portal.org/smash/get/diva2:382726/FULLTEXT01.pdf. Accessed November 3, 2017.

Svensson, M., Zetterqvist, A., \& Ingerman, А̊. (2012). On young people's experience of systems in technology. International Journal of Technology and Design Education, 17(1), 66-77.

Trist, E., \& Murray, H. (Eds.). (1993). The social engagement of social science. Volume II: The sociotechnical perspective. Philadelphia, PA: University of Pennsylvania.

Vygotsky, L. (1986). Thought and language. Cambridge, MA: MIT Press.

Wertsch, J. V. (1998). Mind as action. New York, NY: Oxford University Press. 